\title{
Comparison of Treatment Options for Refractory Opioid Use Disorder in the United States and Canada: a Narrative Review
}

\author{
Simeon Kimmel, MD, MA ${ }^{7,2,3}{ }_{\mathbb{D}}$, Paxton Bach, MD, MSc ${ }^{4,5}$, and Alexander Y. Walley, MD, MSc ${ }^{7,3,6}$ \\ 'Grayken Center for Addiction, Clinical Addiction Research and Education Unit, Section of General Internal Medicine, Department of Medicine, \\ Boston Medical Center, Boston, MA, USA; ${ }^{2}$ Section of Infectious Diseases, Department of Medicine, Boston Medical Center, Boston, MA, USA; \\ ${ }^{3}$ Boston University School of Medicine, Boston, MA, USA; ${ }^{4}$ British Columbia Centre on Substance Use, Vancouver, Canada; ${ }^{5}$ Department of \\ Medicine, The University of British Columbia, Vancouver, Canada; ${ }^{6}$ Massachusetts Department of Public Health, Boston, MA, USA.
}

Amidst the opioid overdose crisis, there are increased efforts to expand access to medications for opioid use disorder (MOUD). Hospitalization for the complications of substance use in the United States (US) provides an opportunity to initiate methadone, buprenorphine, and extended release naltrexone and link high-risk, not otherwise engaged, patients into outpatient care. However, treatment options for patients are quickly exhausted when these medications are not desired, tolerated, or beneficial. As an example, we discuss the case of a man who was hospitalized 27 times over 2 years for complications related to his opioid use disorder (OUD), including recurring methicillin-resistant Staphylococcus aureus vertebral osteomyelitis, increasing antimicrobial resistance, new infections, and multiple overdoses in and out of the hospital. The patient suffered these complications despite efforts to treat his OUD with methadone and buprenorphine while hospitalized, and repeated attempts to link him to outpatient care. We use this case to review evidence-based treatments for refractory OUD, which are not approved in the US, but are available in Canada. If hospitalized in Vancouver, Canada, this patient could have been offered slow-release oral morphine and injectable opioid agonist therapy, as well as access to sterile syringes and injection equipment at an in-hospital supervised injection facility. Each of these approaches is supported by evidence and has been implemented successfully in Canada, yet none are available in the US. In order to combat the multiple harms from opioids, it is critical that we consider every evidence-based tool.

KEY WORDS: opioid use disorder; injection drug use; opioid agonist therapy; harm reduction.

J Gen Intern Med 35(8):2418-26

DOI: $10.1007 / \mathrm{s} 11606-020-05920-0$

(c) Society of General Internal Medicine 2020

\section{INTRODUCTION}

Efforts to integrate addiction care into general medical settings have increased in response to the opioid overdose crisis, which

Received August 28, 2019

Accepted May 8, 2020

Published online May 27, 2020 claimed nearly 50,000 American lives in $2017^{1-4}$. Hospitalizations for overdose, injection drug-associated infections, trauma, or other medical issues are opportunities to engage high-risk patients and initiate medications for opioid use disorder (MOUD), which in the United States (US) include methadone, buprenorphine, and extended release naltrexone ${ }^{1,}$ ${ }^{5-7}$. Methadone is a long-acting, full opioid agonist delivered daily in specialized clinics to manage opioid use disorder (OUD) in the US ${ }^{7}$. Buprenorphine is a partial opioid agonist with a ceiling effect, a flattening of the dose response curve at higher doses, co-formulated with naloxone to deter intravenous use that is prescribed using a special waiver from the Drug Enforcement Agency ${ }^{7}$. Finally, extended release naltrexone is a long-acting injectable opioid antagonist which requires 7 days without opioids for initiation without precipitated withdrawal ${ }^{7}$. Methadone and buprenorphine have been shown to reduce all-cause mortality in people who have experienced an overdose $\mathrm{e}^{8,9}$, decrease against medical advice (AMA) discharges ${ }^{10-12}$, and reduce readmission in patients with injection drug-related infections ${ }^{13}$. Unfortunately, patients with OUD for whom methadone, buprenorphine, and extended release naltrexone are not desired, tolerable, or beneficial rapidly exhaust their treatment options ${ }^{14}$. Such patients, who have received multiple trials of evidence-based treatments without reduction in drug use, with multiple negative health and social consequences of drug use, and/or with persistent high risk for overdose, may be termed as having "refractory OUD"

Reducing barriers to MOUD is central to an evidence-based response to the opioid overdose crisis. In-hospital initiation of MOUD with linkage to outpatient care has emerged as an important way to engage high-risk patients into life-saving care $^{13,16,17}$. Strategies used successfully elsewhere should be considered to help improve care in the US ${ }^{18}$. We present the case of a patient with refractory OUD hospitalized with recurrent infections in Boston, MA, US, and compare the OUD treatment and harm reduction options available in Boston and Vancouver, British Columbia, Canada, to illustrate the care options across different settings. 


\section{CASE}

A middle-aged, unhoused male presented to the emergency department with back pain, low-grade fevers, and injection drug use in December 2017. His past medical history is notable for OUD with injection heroin and fentanyl use. Previous complications include 27 admissions in the prior 2 years, 22 of which ended in AMA discharges for vertebral osteomyelitis with evolving antimicrobial resistance (methicillin-resistant Staphylococcus aureus (MRSA) with emerging resistance to vancomycin and daptomycin) in the setting of incomplete antibiotic courses, sternal osteomyelitis, tenosynovitis, and bacteremias with multiple organisms (Fig. 1). He also experienced multiple overdoses, including one during a prior admission in the hospital restroom after injecting drugs from outside the hospital, which required rescue with naloxone.

He developed OUD more than a decade ago, after receiving prescription opioids for back pain; he initiated heroin after they were stopped. His longest period of abstinence was 7 months while treated with buprenorphine-naloxone shortly after initiating heroin. He continued to receive a monthly prescription for buprenorphine from an outside provider, though after 7 months, he reported little benefit and started using heroin again, while taking buprenorphine. He was treated with methadone in the past, but left care before his dose could be increased high enough to adequately control his cravings.

The addiction service consulted with the primary team during most of his previous hospitalizations. Treatment with buprenorphine-naloxone and methadone was attempted several times in the hospital with a plan to link to an outpatient methadone clinic without interruption. The patient did not attend outpatient methadone appointments and declined outpatient buprenorphine with increased monitoring and shorter prescription intervals. The patient was unable to abstain from opioids for a sufficient period to initiate oral or extended release naltrexone. He utilized a syringe service program out of the hospital, received further counseling about safer injection practices, and naloxone rescue kits. His psychiatric history was notable for self-reported depression, but inpatient psychiatric consultants had attributed his symptoms to substance use. He had been previously employed but was on disability with few social supports.

During this hospitalization for back pain and fever, he was diagnosed with a vancomycin-insensitive Staphylococcus aureus (VISA) epidural phlegmon with no drainable collection at the site of his recurrent vertebral osteomyelitis. His inpatient providers offered withdrawal and pain management and urged him to remain in the hospital to receive antibiotics. The patient successfully completed 6 weeks of ceftaroline and buprenorphine-naloxone in the acute care hospital as no subacute care facilities accepted him. He acknowledged sporadic injection fentanyl use while in the hospital and had syringes confiscated by security. After completion of antibiotics, he was discharged to a local homeless shelter with a 7-day prescription for buprenorphine-naloxone until he could see his outpatient physician. The patient continued to inject opioids following this presentation and had several more hospital admissions for infections with similar courses.

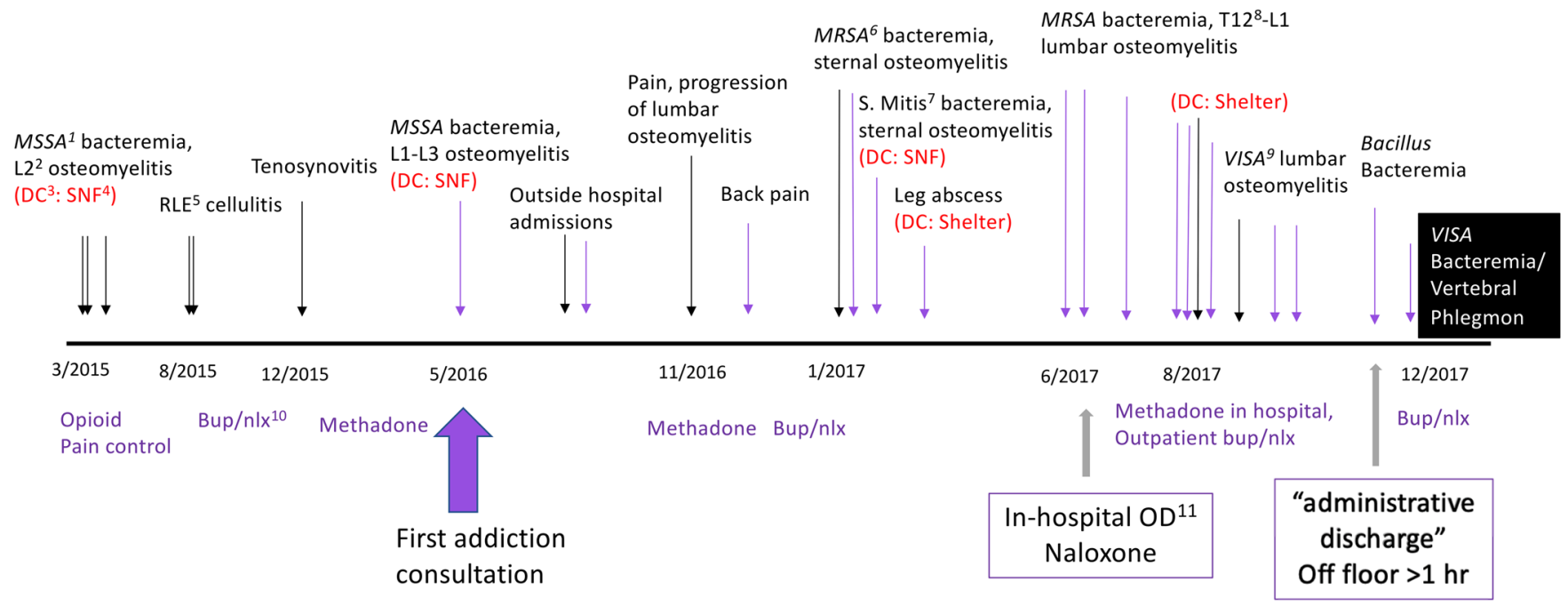

$\downarrow=$ Admission without addiction consultation

= Opioid use disorder care
$=$ Discharged; All other hospitalization resulted in AMA discharges
$=$ Admission with addiction consultation

Figure 1 Hospitalizations and addiction interventions, 2015-2017. MSSA, methicillin-sensitive Staphylococcus aureus; L, lumbar; DC, discharge; SNF, subacute nursing facility; RLE, right lower extremity; MRSA, methicillin-resistant Staphylococcus aureus; S. mitis, streptococcal mitis; T, thoracic; VISA, vancomycin insensitive Staphylococcus aureus; Bup/nlx, buprenorphine/naloxone; OD, overdose; AMA, against medical advice discharge. 


\section{Case Discussion}

This patient's case highlights some of the challenges of treating individuals with refractory OUD and serious bacterial infections in general medical settings despite access to addiction consultation services, buprenorphine, methadone, peer supports, and improved handoffs to bridge clinics following hospitalization. Alternative strategies to manage refractory OUD are necessary for some patients to reduce the harms from injection drug use, particularly when a patient is not interested or does not benefit from the medications approved for OUD in the US.

In this case, the patient had experience with methadone but could not tolerate attending a daily clinic and did not achieve an effective dose. As methadone is long acting with a variable halflife, the dose is raised slowly in the outpatient setting. While he received higher doses when hospitalized, he did not attend outpatient appointments and declined methadone on subsequent admissions. The patient requested buprenorphine-naloxone while hospitalized for management of both OUD and pain but still had frequent AMA discharges. At the time of these hospitalizations, long-acting injectable formulations of buprenorphine and naltrexone were not available to inpatients with OUD in our hospital system. When these additional treatments become available, they will be options for him (Table 1).

\section{TREATMENT OPTIONS AVAILABLE IN CANADA}

Like the US, Canada has experienced a rapid rise in overdose deaths first due to rising prescription opioid availability and subsequently due to contamination of the heroin supply with fentanyl ${ }^{21}$. However, the Canadian national practice guidelines for OUD present several additional treatment options that are not available in the US and which may have benefitted this patient ${ }^{19}$ (Table 1). In this narrative review, we included evidence from the most recent US and Canadian national governmental clinical guidelines for treatment of OUD as well as the guidelines produced by the British Columbia Ministry of Health in conjunction with the British Columbia Centre on Substance Use. To demonstrate the variability of OUD care by location, we selected the British Columbia guidelines because they specifically focus on OUD treatments which are restricted in the US and employed a structured literature review to identify and weight evidence according to its quality, prioritizing meta-analyses of randomized control trials, individual randomized control trials, observational reports and lastly expert opinion. Focusing on systematic reviews and randomized control trials, we selected several studies from North America and Europe which were cited in the practice guidelines to elucidate clinical comparisons among the treatment options. We also included an additional systematic review which was published after the practice guidelines and selected several studies which were not included in the guidelines due to study design or specified outcome but nonetheless have clinical and policy importance (e.g., pharmacodynamics, side effects, quality of life, satisfaction, cost-effectiveness). For harm reduction approaches included in this review which were not directly addressed by governmental treatment guidelines, we also selected key systematic reviews and observational studies. Where the quality of evidence is weak, we note that and cite relevant narrative reviews or commentaries. These

Table 1 A Comparison of Modalities for the Treatment of Opioid Use Disorder Between Vancouver, British Columbia, Canada, and Boston, MA, US ${ }^{7}, 19,20$

\begin{tabular}{|c|c|c|}
\hline & Vancouver & Boston \\
\hline Buprenorphine/naloxone & $\begin{array}{l}\text { 1st line treatment according to Canadian national } \\
\text { practice guidelines with high-quality evidence, } \\
\text { strong recommendation. Prescribed without spe- } \\
\text { cialized waiver or license. }\end{array}$ & $\begin{array}{l}\text { Schedule } 3^{1} \text {. Approved for treatment of OUD; } \\
\text { prescribed with specialized waiver. Most common } \\
\text { formulation is daily sublingual. Also available in } \\
\text { buprenorphine mono-product as implant or sub- } \\
\text { cutaneous injection. }\end{array}$ \\
\hline Methadone & $\begin{array}{l}\text { 2nd line medication according to Canadian } \\
\text { national practice guidelines with high-quality } \\
\text { evidence, strong recommendation. Prescribed } \\
\text { without specialized waiver or license, though } \\
\text { remains subject to prescribing requirements as } \\
\text { established by each individual province. Dis- } \\
\text { pensed in community pharmacies. }\end{array}$ & $\begin{array}{l}\text { Schedule } 2^{2} \text {. Approved for use in specially } \\
\text { licensed opioid treatment program (OTP) and } \\
\text { acute inpatient hospital settings for withdrawal } \\
\text { management. Can be prescribed for pain, not } \\
\text { OUD, outside of OTP. }\end{array}$ \\
\hline Slow-release oral morphine & $\begin{array}{l}\text { 3rd line medication according to Canadian } \\
\text { national practice guidelines, with moderate-quality } \\
\text { evidence, strong recommendation. Suggested fol- } \\
\text { lowing consultation with an experienced addiction } \\
\text { practitioner. }\end{array}$ & $\begin{array}{l}\text { FDA approved for use in chronic pain. Use of this, } \\
\text { or any other opioid agonist other than methadone } \\
\text { or buprenorphine, is prohibited by the Controlled } \\
\text { Substances Act. }\end{array}$ \\
\hline Extended release injectable naltrexone & $\begin{array}{l}\text { Not approved by Health Canada. Available } \\
\text { through a Special Access Program only. }\end{array}$ & $\begin{array}{l}\text { FDA-approved treatment of opioid use disorder } \\
\text { without specialized waiver or license to prescribe. }\end{array}$ \\
\hline $\begin{array}{l}\text { Injectable opioid agonist therapy (with } \\
\text { hydromorphone or diacetylmorphine) }\end{array}$ & $\begin{array}{l}\text { Alternative approach for the treatment of patients } \\
\text { refractory to oral opioid agonist therapy or at } \\
\text { particularly high risk of overdose }\end{array}$ & $\begin{array}{l}\text { Federally prohibited for use as treatment for opioid } \\
\text { use disorder according to the Controlled Substance } \\
\text { Act. }\end{array}$ \\
\hline
\end{tabular}

${ }^{1}$ According to the Controlled Substances Act, a drug with moderate to low potential for physical and psychological dependence

${ }^{2}$ According to the Controlled Substances Act, a drug with a high potential for abuse

${ }^{3}$ See Office of Diversion Control D. Practitioner's Manual: An Informational Outline of the Controlled Substances Act, Section 6. 2006 which is available at https://www.deadiversion.usdoj.gov/pubs/manuals/pract/pract_manual012508.pdf 
studies and their conclusions are summarized in Table 2. We explicitly focus on MOUD and harm reduction approaches over behavioral interventions due to the strength of evidence and their central role in the management of OUD, especially in inpatient medical settings ${ }^{22}$. Studies were largely conducted among adult outpatients, but the treatments are nonetheless available to hospitalized patients in Vancouver, Canada.

\section{Medications for Opioid Use Disorder: Pharmacy-Dispensed Daily Methadone}

In Canada, pharmacists at retail pharmacies can dispense and witness daily ingestion of methadone after a primary care physician writes a prescription for methadone for OUD ${ }^{15,23}$. Pharmacy-based methadone reduces barriers, improves access, and blunts stigma directed toward methadone treatment $^{23}$. In the province of British Columbia, as of 2018, there were 1354 pharmacies operating, 1131 of which dispensed opioid agonist treatment (OAT), including methadone, to 29,667 patients $^{24,25}$. Though concerns about confidentiality, risk of diversion, safety of pharmacy staff and clients, and crime in the surrounding neighborhood, as well as need for pharmacy training and regulatory frameworks have been raised, these concerns have largely been refuted in the literature $^{23}$. In the US-based opioid treatment system, regulations only allow for the witnessed administration of methadone for OUD through clinics typically separate from the rest of the healthcare system. In the patient's case, pharmacy-based methadone may have enabled the patient to access methadone daily in his community so he could reach an effective dose and adhere to treatment.

\section{Medications for Opioid Use Disorder: Slow- Release Oral Morphine}

The 2018 Canadian national clinical practice guidelines include slow-release oral morphine (SROM) as a third-line option for patients with OUD refractory to buprenorphine and methadone ${ }^{19}$. Formulated to deliver morphine at a controlled dose over $24 \mathrm{~h}$, SROM has been used to treat OUD in Europe since the 1990s and is the most common treatment in Austria $^{26,27}$. It is similar to other long-acting $m u$-opioid receptor agonists such as methadone, but has fewer cardiotoxicities, drug-drug interactions, and can be titrated more rapidly. The peak effect is delayed $6-8 \mathrm{~h}^{28}$.

A recent meta-analysis including four randomized control trials showed that SROM is equivalent to methadone in retaining patients in treatment and reducing illicit heroin use ${ }^{29}$. In two of these studies, SROM was associated with reduced cravings compared to methadone, though this outcome was not included in the meta-analysis ${ }^{30,31}$. Other small trials have suggested that, compared to methadone, SROM improves depression, anxiety, and treatment satisfaction, but evidence is mixed on quality-oflife improvements compared to treatment with methadone or buprenorphine ${ }^{32-36}$. As the majority of SROM trials are small and unblinded, further studies are necessary.
In practice, community pharmacists dispense and witness SROM ingestion daily like methadone. Treatment can be initiated in the community, or by an in-hospital physician who arranges transition to a community provider on discharge. Pharmacists witness ingestion of slow-release beads from opened capsules to minimize diversion risk. Given the more predictable half-life compared to methadone, the dose can be increased every $48 \mathrm{~h}$ until a patient is stabilized ${ }^{15}$. When heroin is the most common opioid used by a person with OUD, it is difficult to distinguish SROM from illicit opioids on toxicology testing, as both test positive for opiates on screening tests. However, as fentanyl use has increased, clinicians can now directly detect fentanyl in urine toxicology, easing this concern.

SROM therapy may have been beneficial for this patient who suffered from pain in addition to OUD. Additionally, he may have successfully engaged in treatment with a more rapid titration to an effective dose.

\section{Medications for Opioid Use Disorder: Injectable Opioid Agonist Therapy}

Injectable opioid agonist therapy (iOAT) with either hydromorphone or diacetylmorphine (pharmaceutical heroin) is available in Canada and several Western European countries for the treatment of refractory OUD ${ }^{20}$. Trials of injectable diacetylmorphine demonstrate a reduction in illicit substance use, improved treatment retention, decrease in illegal activities and incarceration, and a possible mortality benefit ${ }^{37}$. Quality of life measures and reports of treatment satisfaction are also better in patients treated with diacetylmorphine compared to methadone ${ }^{38,39}$. A recent, large Canadian study evaluated injectable hydromorphone as an alternative to diacetylmorphine and found that when compared with diacetylmorphine, there was a non-inferior reduction in opioid use ${ }^{40}$.

There are three iOAT models in Canada: (1) dedicated supervised iOAT programs, (2) iOAT programs integrated into outpatient medical clinics, or (3) pharmacy-based iOAT programs $s^{20}$. All approaches have been adopted successfully. Patients must have a history of injection drug use without coexisting alcohol or sedative use disorder and meet criteria for severe OUD that has not benefitted from oral treatments or remain at high risk of overdose. Two independent physicians screen for eligibility. Following acceptance, the patient is treated with escalating doses of medication twice daily under the supervision of a nurse, until clinically stable. Then, patients present two or three times daily for witnessed selfadministration of the medication, either intravenously in the upper extremities or by intramuscular injection in large leg muscles. A long-acting opioid formulation such as methadone or SROM is typically given in the evenings to provide treatment at night ${ }^{20}$.

Given the logistical requirements and resources involved in iOAT treatment, this is an addiction specialist-led approach for severe OUD. Multiple cost-effectiveness analyses have 
Table 2 Summary of Cited Evidence Related to Sustained Release Oral Morphine, Injectable Opioid Agonist Therapy, and Hospital-Based Syringe and Supervised Injection Facilities

\section{Study}

Pharmacy-based methadone

Bruneau J, Ahamad K, Goyer M-È, et al.

Management of opioid use disorders: a national

clinical practice guideline. Can Med Assoc J.

2018;190(9):E247-E257.

Bach P, Hartung D. Leveraging the role of

community pharmacists in the prevention,

surveillance, and treatment of opioid use

disorders. Addict Sci Clin Pract. 2019;14(1):30.

Sustained release oral morphine

Bruneau J, Ahamad K, Goyer M-È, et al.

Management of opioid use disorders: a national

clinical practice guideline. Can Med Assoc J.

2018;190(9):E247-E257.

British Columbia Centre on Substance Use and

British Columbia Ministry of Health.

A Guideline for the Clinical Management of

Opioid Use Disorder 2017.

*Mitchell TB, White JM, Somogyi AA, Bochner

F. Comparative pharmacodynamics and

pharmacokinetics of methadone and slow-release

oral morphine for maintenance treatment of opioid

dependence. Drug Alcohol Depend.

2003;72(1):85-94.

*Klimas J, Gorfinkel L, Giacomuzzi SM, et al.

Slow release oral morphine versus methadone for

the treatment of opioid use disorder. BMJ Open.

2019;9(4): e25799.

Falcato L, Beck T, Reimer J, Verthein U. Self-

Reported Cravings for Heroin and Cocaine

During Maintenance Treatment With Slow-

Release Oral Morphine Compared With Metha-

done. J Clin Psychopharmacol. 2015;35(2):150-

157.

Hämmig R, Köhler W, Bonorden Kleij K, et al.

Safety and tolerability of slow-release oral mor-

phine versus methadone in the treatment of opioid

dependence. J Subst Abuse Treat.

2014;47(4):275-281.

Eder H, Jagsch R, Kraigher D, Primorac A

Ebner N, Fischer G. Comparative study of the

effectiveness of slow-release morphine and meth-

adone for opioid maintenance therapy. Addiction.

2005;100(8):1101-1109.

Kastelic A, Dubajic G, Strbad E. Slow-release

oral morphine for maintenance treatment of opioid

addicts intolerant to methadone or with inadequate

withdrawal suppression. Addiction.

2008;103(11):1837-1846.

Mitchell TB, White JM, Somogyi AA, Bochner

F. Slow-release oral morphine versus methadone:

a crossover comparison of patient outcomes and

acceptability as maintenance pharmacotherapies

for opioid dependence. Addiction.

2004;99(8):940-945.

Giacomuzzi S, Kemmler G, Ertl M, Riemer Y.

Opioid Addicts at Admission vs. Slow-Release

Oral Morphine, Methadone, and Sublingual

Buprenorphine Maintenance Treatment Partici-

pants. Subst Use Misuse. 2006;41(2):223-244.

Verthein U, Beck T, Haasen C, Reimer J. Mental

Symptoms and Drug Use in Maintenance

Treatment with Slow-Release Oral Morphine

Compared to Methadone: Results of a Random-

ized Crossover Study. Eur Addict Res.

2014;21(2):97-104.

Injectable opioid agonist therapy (iOAT)

British Columbia Centre on Substance Use and

British Columbia Ministry of Health. Guidance

Study type

Conclusion

Canadian national practice guideline; structured literature review to identify and weight evidence according to strength based on a traditional research hierarchy Narrative review

Canadian national practice guideline; structured literature review to identify and weight evidence according to strength based on a traditional research hierarchy

Clinical Guideline of Province of British Columbia; structured literature review to identify and weight evidence according to strength based on a traditional research hierarchy

Open-label, cross-over design $(n=14,7$ with and 7 without adequate control of OUD with methadone)

Systematic review and meta-analysis of randomized control trials

Open-label, randomized, cross-over trial of per protocol sample $(n=157)$

International, multi-center two-phase, two-way cross-over randomized control trial $(n=276)$

Double-blind, cross-over randomized control trial $(n=64)$

Prospective, open, non-comparative multicenter study $(n=67)$

Open-label, cross-over study $(n=18)$

Open-label, randomized control trial $(n=240)$

Open-label, multinational/multisite cross-over trial $(n=157)$; Study analyzed as per protocol analysis

Clinical Guideline of Province of British Columbia; structured literature review to identify and weight evidence according to
High-quality evidence for methadone; strong recommendation; guidelines presume pharmacy-based dosing as this is standard of care in Canada.

Pharmacy-based methadone is standard of care in several countries, offers improved flexibility, and has the capacity to expand treatment access.

Moderate evidence, strong recommendation.

Moderate evidence, strong recommendation.

For those without OUD control with methadone, SROM improved symptoms; for those with OUD control with methadone, symptoms were similarly controlled.

SROM is equivalent to methadone with respect to patient retention and reductions in heroin use but associated with less cravings; quality of RCTs was low to moderate.

Heroin cravings were significantly lower when treated with SROM than with methadone.

SROM was associated with greater treatment satisfaction, fewer cravings, lower stress; methadone was associated with more QTc prolongation.

No differences in retention or illicit substance use between SROM and methadone; patients treated with SROM had lower depression, anxiety, and physical complaints.

SROM resulted in fewer side effects among those intolerant to methadone; SROM resulted in reduction of cravings for opioids for those with inadequate response.

SROM was associated with improved social functioning, weight loss, fewer side effects, less cravings, and more reports of "drug liking" and feeling normal.

Buprenorphine and methadone had fewer bothersome physical symptoms and improved quality of life.

Improved mental symptoms and treatment satisfaction with SROM; no differences in illicit drug or alcohol consumption.

Evidence-based, high-intensity treatment for those who have not benefited from oral therapies. 
Table 2. (continued)

\begin{tabular}{lll}
\hline \hline Study & Study type & Conclusion \\
\hline $\begin{array}{l}\text { for Injectable Opioid Agonist Treatment for } \\
\text { Opioid Use Disorder 2017. }\end{array}$ & $\begin{array}{l}\text { strength based on a traditional research } \\
\text { herri M, Davoli M, Perucci CA. Heroin } \\
\text { Cochrane Review; 8 studies included }\end{array}$ & $\begin{array}{l}\text { Added value to prescription heroin alongside } \\
\text { maintenance for chronic heroin-dependent indi- } \\
\text { viduals. Cochrane Database Syst Rev. December }\end{array}$ \\
$\begin{array}{ll}\text { use disorder; decrease in use of illicit } \\
\text { substances and criminal activity; possible } \\
\text { mortality reduction; increase in treatment } \\
\text { retention. }\end{array}$ \\
$\begin{array}{l}\text { * Karow A, Reimer J, Schäfer I, Krausz M, } \\
\text { Haasen C, Verthein U. Quality of life under } \\
\text { maintenance treatment with heroin versus } \\
\text { methadone in patients with opioid dependence. }\end{array}$ & Randomized control trial $(n=1015)$ & $\begin{array}{l}\text { Impred to methadone; greatest benefit in meas- } \\
\text { pared } \\
\text { ures of physical health. }\end{array}$ \\
\hline
\end{tabular}

Drug Alcohol Depend. 2010;112(3):209-215.

*Marchand KI, Oviedo-Joekes E, Guh D,

Brissette S, Marsh DC, Schechter MT. Client satisfaction among participants in a randomized trial comparing oral methadone and injectable diacetylmorphine for long-term opioid-dependency. BMC Health Serv Res. 2011;11(1).

Oviedo-Joekes E, Guh D, Brissette S, et al. Hydromorphone Compared With Diacetylmorphine for Long-term Opioid Dependence. JAMA Psychiatry. 2016;73(5):447.

Byford S, Barrett B, Metrebian N, et al. Costeffectiveness of injectable opioid treatment $\mathrm{v}$. oral methadone for chronic heroin addiction. Br J Psychiatry. 2013;203(5):341-349. doi:https://doi. org/10.1192/bjp.bp.112.111583

*Nosyk B, Guh DP, Bansback NJ, et al. Costeffectiveness of diacetylmorphine versus methadone for chronic opioid dependence refractory to treatment. Can Med Assoc J. 2012;184(6):E317E328.

*Dijkgraaf MGW, van der Zanden BP, de Borgie CAJM, Blanken P, van Ree JM, van den Brink W. Cost utility analysis of co-prescribed heroin compared with methadone maintenance treatment in heroin addicts in two randomised trials. BMJ. 2005;330(7503):1297.

*Bansback N, Guh D, Oviedo-Joekes E, et al. Cost-effectiveness of hydromorphone for severe opioid use disorder: findings from the SALOME randomized clinical trial. Addiction. 2018;113(7):1264-1273.

Randomized control trial $(n=251)$; injectable diacetylmorphine and hydromorphone groups were double blinded

Double-blind, non-inferiority trial $(n=202)$

Cost-effectiveness study based on a multisite, open-label, randomized control trial $(n=301)$

Semi-Markov cohort model with data from the North American Opiate Medication Initiative Trial

Cost utility analysis using data from 6 methadone maintenance programs in the Netherlands $(n=430)$

Cost-effectiveness analysis as part of doubleblinded RCT; lifetime analysis extrapolated costs and outcomes using a decision analytic cohort model $(n=202)$

Harm reduction approaches: hospital-based syringe service programs and supervised injection facilities Sharma M, Lamba W, Cauderella A, Guimond TH, Bayoumi AM. Harm reduction in hospitals. Harm Reduct J. 2017;14(1):32.

Rachlis BS, Kerr T, Montaner JSG, Wood E. Harm reduction in hospitals: is it time? Harm Reduct J. 2009;6:19.

Brooks HL, O'Brien DC, Salvalaggio G, Dong $\mathrm{K}$, Hyshka E. Uptake into a bedside needle and syringe program for acute care inpatients who inject drugs. Drug Alcohol Rev. April

2019:dar.12930.

Potier C, Laprévote V, Dubois-Arber F, Cottencin O, Rolland B. Supervised injection services: What has been demonstrated? A systematic literature review. Drug Alcohol Depend. 2014;145:48-68.

Ti L, Buxton J, Harrison S, et al. Willingness to access an in-hospital supervised injection facility among hospitalized people who use illicit drugs. $J$ Hosp Med. 2015;10(5):301-306.

\section{Narrative review}

Commentary

Retrospective cohort study of inpatient syringe service program $(n=556)$

Systematic literature review (75 studies; multiple study types included)

Cross sectional study of two cohorts of people who use drugs $(n=732)$
Improved client satisfaction among individuals treated with injectable diacetylmorphine and hydromorphone.

Injectable hydromorphone is as effective as injectable diacetylmorphine; fewer adverse events.

Costs for injectable diacetylmorphine were significantly higher than injectable methadone or oral methadone.

Injectable diacetylmorphine may be more effective and less costly than methadone among people with refractory OUD using 1-, 5, and 10-year lifetime horizons.

Co-prescribing of diacetylmorphine with methadone is cost effect compared to methadone alone.

Injectable hydromorphone may be cost saving compared to injectable diacetylmorphine.

\footnotetext{
*Study selected by authors; not included in cited governmental practice guidelines
}

Further research is needed on hospital-based syringe service programs and hospital-based supervised injection.

Need for further evaluation.

$56 \%$ of inpatients who injected drugs were offered syringes; $37 \%$ of patients offered syringes, accepted; men and women were equally likely to be offered syringes, but females were more likely to accept. Supervised injection sites are effective in attracting marginalized people who inject drugs, improving access to primary care, reducing overdose and promote safer injection practices; additionally, they reduce public drug use, and dropped syringes without increasing crime.

$68.2 \%$ stated willingness to access an inhospital supervised injection facility; having recently used in a supervised injection facility, daily heroin injection, or recent hospitalization were associated with willing to access a supervised injection facility. 
suggested a net benefit compared to oral methadone for refractory OUD ${ }^{41-44}$. Though iOAT is more costly, there are significant savings from reduction in criminal activity and improved treatment retention ${ }^{42}$.

When asked theoretically about this treatment as it is not available in the US, this patient showed an interest in iOAT, particularly expressing his concerns about overdose from fentanyl, inability to consistently utilize safer injection practices, and ongoing cravings with other treatments.

\section{Additional Harm Reduction Approaches: Hospital-Based Syringe Services and Super- vised Injection Sites}

There are multiple strategies to reduce the harms associated with substance use while hospitalized and/or after discharge for individuals who use substances despite access to methadone, buprenorphine, SROM, or $\mathrm{iOAT}^{45}$. These approaches can be offered alongside other evidence-based treatments. Promoting abstinence alone may drive patients to hide their drug use in the hospital or leave $\mathrm{AMA}^{10,46}$. In several Canadian cities, patients are provided sterile syringes, and in Vancouver and Edmonton, they are offered access to a supervised injection space within the hospital, staffed by peers or nurses. The supervising staff provide access to sterile equipment, instruction on improving injecting practices, and immediate medical attention should an overdose occur. Sterile syringes are routinely recommended for people who inject drugs in the US, but access is geographically limited and rarely, if ever offered in the hospital setting ${ }^{47}$. Many patients who inject drugs and are hospitalized in Canada utilize syringe services if they are available ${ }^{48}$.

While hospital-based supervised injection facilities are not well studied, there is robust evidence supporting communitybased supervised injection facilities. They attract marginalized individuals, promote safer injection practices, and reduce overdose mortality and public injecting without increasing drug use or neighborhood crime ${ }^{49}$. Following the publication of a needs assessment showing two-thirds of individuals who injected drugs would utilize hospital-based supervised injection facilities if they were hospitalized in Vancouver, Canada, several are operating. They are particularly popular among those who inject heroin daily, have used illicit drugs in the hospital previously, or have recently used a supervised injection facility ${ }^{50}$.

These harm reduction tools may have benefited this patient and helped prevent overdose and recurrent infections. Though he did access sterile syringes in the community, he did not always use sterile techniques while attempting to hide his drug use, including in the hospital where syringes were confiscated. Given his ambivalence toward decreasing his drug use, these strategies may have decreased the risk from such use and facilitated a more therapeutic alliance with his care team.

\section{CONCLUSION}

While efforts to expand access to methadone, buprenorphine, and extended release naltrexone are crucial to treat OUD, these medications are not universally desired, tolerated, or beneficial. Slow-release oral morphine, injectable opioid agonist therapy, and provision of sterile syringes and injection equipment at in-hospital supervised injection facilities are evidencebased strategies used to treat and reduce the negative consequences of injection drug use in Canada, while pharmacybased distribution of methadone has the potential to significantly improve access to this life-saving medication for those who need it. In the midst of the opioid overdose crisis, barriers to implementing these approaches in the US should be addressed.

Acknowledgments: The authors wish to acknowledge the patient whose case is presented for agreeing to share his story and for reviewing the manuscript. Dr. Kimmel was supported by the National Institute on Drug Abuse (NIDA) including the Clinical Addiction Research and Education Unit and Fellows Immersion Training Program (R25DA013582), Research in Addiction Medicine Scholars Program (R25DA033211), and the National Institute of Allergy and Infectious Diseases through the Boston University Clinical HIV/AIDS Training Program (5T32AI052074). Dr. Bach was also supported by the Research in Addiction Medicine Scholars Program (R25DA033211) and is supported by the Michael Smith Foundation for Health Research. Dr. Walley reports support from the Clinical Addiction Research and Education Unit (R25DA013582).

Corresponding Author: Simeon Kimmel, MD, MA; Grayken Center for Addiction, Clinical Addiction Research and Education Unit, Section of General Internal Medicine, Department of Medicine, Boston Medical Center, Boston, MA, USA (e-mail: Simeon.kimmel@bmc.org).

\section{Compliance with Ethical Standards:}

Conflict of Interest: The authors declare that they do not have a conflict of interest.

\section{REFERENCES}

1. Springer SA, Korthuis PT, del Rio C. Integrating Treatment at the Intersection of Opioid Use Disorder and Infectious Disease Epidemics in Medical Settings: A Call for Action After a National Academies of Sciences, Engineering, and Medicine Workshop. Ann Intern Med. 2018. doi:https://doi.org/10.7326/M18-1203

2. Liebschutz JM, Crooks D, Herman D, et al. Buprenorphine treatment for hospitalized, opioid-dependent patients: a randomized clinical trial. JAMA Intern Med. 2014;174(8):1369-1376. doi:https://doi.org/10.1001/ jamainternmed.2014.2556

3. Shanahan CW, Beers D, Alford DP, Brigandi E, Samet JH. A Transitional Opioid Program to Engage Hospitalized Drug Users. J Gen Intern Med. 25(8):803-808. doi:https://doi.org/10.1007/s11606-0101311-3

4. Scholl L, Seth P, Kariisa M, Wilson N, Baldwin G. Drug and OpioidInvolved Overdose Deaths - United States, 2013-2017. MMWR Morb Mortal Wkly Rep. 2018;67(5152). doi:https://doi.org/10.15585/mmwr. mm6751521e1

5. Ronan M V., Herzig SJ. Hospitalizations Related To Opioid Abuse/ Dependence And Associated Serious Infections Increased Sharply, 200212. Health Aff. 2016;35(5):832-837. doi:https://doi.org/10.1377/hlthaff. 2015. 1424

6. Rosenthal ES, Karchmer AW, Theisen-Toupal J, Castillo RA, Rowley CF. Suboptimal Addiction Interventions for Patients Hospitalized with Injection Drug Use-Associated Infective Endocarditis. Am J Med. 2016;129(5):481-485. doi:https://doi.org/10.1016/j.amjmed.2015.09. 024 
7. Substance Abuse and Mental Health Services Administration. Medications for Opioid Use Disorder. Treatment Improvement Protocol (TIP) Series 63, Full Document. Rockville, MD; 2018.

8. Larochelle MR, Bernson D, Land T, et al. Medication for Opioid Use Disorder After Nonfatal Opioid Overdose and Association With Mortality. Ann Intern Med. 2018;169(3):137. doi:https://doi.org/10.7326/M173107

9. Sordo L, Barrio G, Bravo MJ, et al. Mortality risk during and after opioid substitution treatment: systematic review and meta-analysis of cohort studies. BMJ. 2017;357. doi:https://doi.org/10.1136/bmj.j1550

10. Ti L, Ti L. Leaving the hospital against medical advice among people who use illicit drugs: A systematic review. Am J Public Health. 2015;105(12) doi:https://doi.org/10.2105/AJPH.2015.302885

11. McNeil R, Small W, Wood E, Kerr T. Hospitals as a 'risk environment': An ethno-epidemiological study of voluntary and involuntary discharge from hospital against medical advice among people who inject drugs. Soc Sci Med. 2014;105:59-66. doi:https://doi.org/10.1016/J.SOCSCIMED. 2014.01.010

12. Summers PJ, Hellman JL, MacLean MR, Rees VW, Wilkes MS. Negative experiences of pain and withdrawal create barriers to abscess care for people who inject heroin. A mixed methods analysis. Drug Alcohol Depend. 2018;190:200-208. doi:https://doi.org/10.1016/J.DRUGALCDEP.2018.06.010

13. Marks LR, Munigala S, Warren DK, Liang SY, Schwarz ES, Durkin MJ Addiction medicine consultations reduce readmission rates for patients with serious infections from opioid use disorder. Clin Infect Dis. 2018. doi:https://doi.org/10.1093/cid/ciy924

14. Timko C, Schultz NR, Cucciare MA, Vittorio L, Garrison-Diehn C. Retention in medication-assisted treatment for opiate dependence: A systematic review. J Addict Dis. 2016;35(1):22-35. doi:https://doi.org/ 10.1080/10550887.2016.1100960

15. British Columbia Centre on Substance Use and British Columbia Ministry of Health. A Guideline for the Clinical Management of Opioid Use Disorder. 2017.

16. Trowbridge $\mathbf{P}$, Weinstein $\mathbf{Z M}$, Kerensky $\mathbf{T}$, et al. Addiction consultation services - Linking hospitalized patients to outpatient addiction treatment J Subst Abuse Treat. 2017;79:1-5. doi:https://doi.org/10.1016/j.jsat. 2017.05.007

17. Wakeman SE, Metlay JP, Chang Y, Herman GE, Rigotti NA. Inpatient Addiction Consultation for Hospitalized Patients Increases PostDischarge Abstinence and Reduces Addiction Severity. J Gen Intern Med. 2017;32(8):909-916. doi:https://doi.org/10.1007/s11606-0174077-z

18. Priest KC, Gorfinkel L, Klimas J, Jones AA, Fairbairn N, McCarty D. Comparing Canadian and United States opioid agonist therapy policies. Int J Drug Policy. February 2019. doi:https://doi.org/10.1016/j.drugpo. 2019.01.020

19. Bruneau J, Ahamad K Goyer M-È, et al. Management of opioid use disorders: a national clinical practice guideline. Can Med Assoc J. 2018; 190(9):E247-E257. doi:https://doi.org/10.1503/cmaj.170958

20. British Columbia Centre on Substance Use and British Columbia Ministry of Health. Guidance for Injectable Opioid Agonist Treatment for Opioid Use Disorder.; 2017.

21. Fairbairn N, Coffin PO, Walley AY. Naloxone for heroin, prescription opioid, and illicitly made fentanyl overdoses: Challenges and innovations responding to a dynamic epidemic. Int J Drug Policy. 2017;46:172-179. doi:https://doi.org/10.1016/j.drugpo.2017.06.005

22. Carroll KM, Weiss RD. The Role of Behavioral Interventions in Buprenorphine Maintenance Treatment: A Review. Am J Psychiatry. 2017;174(8):738-747. doi:https://doi.org/10.1176/appi.ajp.2016. 16070792

23. Bach P, Hartung D. Leveraging the role of community pharmacists in the prevention, surveillance, and treatment of opioid use disorders. Addict Sci Clin Pract. 2019;14(1):30. doi:https://doi.org/10.1186/s13722-0190158-0

24. College of Pharmacists of British Columbia. Annual Report: 2017/2018 Licensure Statistics.; 2018.

25. Ministry of Mental Health and Addictions BC. Responding to B.C.'s Illegal Drug Overdose Epidemic: Progress Update.; 2018.

26. Mitchell TB, White JM, Somogyi AA, Bochner F. Comparative pharmacodynamics and pharmacokinetics of methadone and slowrelease oral morphine for maintenance treatment of opioid dependence. Drug Alcohol Depend. 2003;72(1):85-94. doi:https://doi.org/10.1016/ s0376-8716(03)00190-x

27. European Monitoring Centre for Drugs and Drug Addiction. Austria Drug Report 2018.; 2018.
28. Johnson F, Wagner G, Sun S, Stauffer J. Effect of Concomitant Ingestion of Alcohol on the In Vivo Pharmacokinetics of KADIAN (Morphine Sulfate Extended-Release) Capsules. J Pain. 2008;9(4):330336. doi:https://doi.org/10.1016/j.jpain.2007.11.009

29. Klimas J, Gorfinkel L, Giacomuzzi SM, et al. Slow release oral morphine versus methadone for the treatment of opioid use disorder. BMJ Open. 2019;9(4):e025799. doi:https://doi.org/10.1136/bmjopen2018-025799

30. Falcato L, Beck T, Reimer J, Verthein U. Self-Reported Cravings for Heroin and Cocaine During Maintenance Treatment With Slow-Release Oral Morphine Compared With Methadone. J Clin Psychopharmacol. 2015;35(2):150-157. doi:https://doi.org/10.1097/jcp. 0000000000000288

31. Hämmig R, Köhler W, Bonorden-Kleij K, et al. Safety and tolerability of slow-release oral morphine versus methadone in the treatment of opioid dependence. J Subst Abuse Treat. 2014;47(4):275-281. doi:https://doi. org/10.1016/j.jsat.2014.05.012

32. Eder H, Jagsch R, Kraigher D, Primorac A, Ebner N, Fischer G. Comparative study of the effectiveness of slow-release morphine and methadone for opioid maintenance therapy. Addiction. 2005;100(8):11011109. doi:https://doi.org/10.1111/j.1360-0443.2005.001128.x

33. Kastelic A, Dubajic G, Strbad E. Slow-release oral morphine for maintenance treatment of opioid addicts intolerant to methadone or with inadequate withdrawal suppression. Addiction. 2008;103(11):1837-1846. doi:https://doi.org/10.1111/j.1360-0443.2008.02334.x

34. Mitchell TB, White JM, Somogyi AA, Bochner F. Slow-release ora morphine versus methadone: a crossover comparison of patient outcomes and acceptability as maintenance pharmacotherapies for opioid dependence. Addiction. 2004;99(8):940-945. doi:https://doi.org/10. $1111 /$ j.1360-0443.2004.00764.x

35. Giacomuzzi S, Kemmler G, Ertl M, Riemer Y. Opioid Addicts at Admission vs. Slow-Release Oral Morphine, Methadone, and Sublingual Buprenorphine Maintenance Treatment Participants. Subst Use Misuse. 2006;41(2):223-244. doi:https://doi.org/10.1080/10826080500391845

36. Verthein U, Beck T, Haasen C, Reimer J. Mental Symptoms and Drug Use in Maintenance Treatment with Slow-Release Oral Morphine Compared to Methadone: Results of a Randomized Crossover Study. Eur Addict Res. 2014;21(2):97-104. doi:https://doi.org/10.1159/000368572

37. Ferri M, Davoli M, Perucci CA. Heroin maintenance for chronic heroindependent individuals. Cochrane Database Syst Rev. 2011. doi:https:// doi.org/10.1002/14651858.CD003410.pub4

38. Karow A, Reimer J, Schäfer I, Krausz M, Haasen C, Verthein U. Quality of life under maintenance treatment with heroin versus methadone in patients with opioid dependence. Drug Alcohol Depend. 2010;112(3):209-215. doi:https://doi.org/10.1016/j.drugalcdep.2010. 06.009

39. Marchand KI, Oviedo-Joekes E, Guh D, Brissette S, Marsh DC, Schechter MT. Client satisfaction among participants in a randomized trial comparing oral methadone and injectable diacetylmorphine for longterm opioid-dependency. BMC Health Serv Res. 2011;11(1). doi:https:// doi.org/10.1186/1472-6963-11-174

40. Oviedo-Joekes E, Guh D, Brissette S, et al. Hydromorphone Compared With Diacetylmorphine for Long-term Opioid Dependence. JAMA Psychiatry. 2016;73(5):447. doi:https://doi.org/10.1001/jamapsychiatry.2016. 0109

41. Byford S, Barrett B, Metrebian N, et al. Cost-effectiveness of injectable opioid treatment v. oral methadone for chronic heroin addiction. $\mathrm{Br} J$ Psychiatry. 2013;203(5):341-349. doi:https://doi.org/10.1192/bjp.bp. 112.111583

42. Nosyk B, Guh DP, Bansback NJ, et al. Cost-effectiveness of diacetylmorphine versus methadone for chronic opioid dependence refractory to treatment. Can Med Assoc J. 2012;184(6):E317-E328. doi:https://doi. org/10.1503/cmaj.110669

43. Dijkgraaf MGW, van der Zanden BP, de Borgie CAJM, Blanken P, van Ree JM, van den Brink W. Cost utility analysis of co-prescribed heroin compared with methadone maintenance treatment in heroin addicts in two randomised trials. BMJ. 2005;330(7503):1297. doi:https://doi.org/ 10.1136/bmj.330.7503.1297

44. Bansback N, Guh D, Oviedo-Joekes E, et al. Cost-effectiveness of hydromorphone for severe opioid use disorder: findings from the SALOME randomized clinical trial. Addiction. 2018;113(7):1264-1273. doi:https://doi.org/10.1111/add.14171

45. Sharma M, Lamba W, Cauderella A, Guimond TH, Bayoumi AM. Harm reduction in hospitals. Harm Reduct J. 2017;14(1):32. doi:https://doi. org/10.1186/s12954-017-0163-0 
46. Rachlis BS, Kerr T, Montaner JSG, Wood E. Harm reduction in hospitals: is it time? Harm Reduct J. 2009;6:19. doi:https://doi.org/10. 1186/1477-7517-6-19

47. Opioid \& Health Indicators Database. https://opioid.amfar.org/indicator/num_SSPs. Accessed December 17, 2019.

48. Brooks HL, O'Brien DC, Salvalaggio G, Dong K, Hyshka E. Uptake into a bedside needle and syringe program for acute care inpatients who inject drugs. Drug Alcohol Rev. April 2019:dar.12930. doi:https://doi.org/10. $1111 /$ dar. 12930

49. Potier C, Laprévote V, Dubois-Arber F, Cottencin O, Rolland B. Supervised injection services: What has been demonstrated? A systematic literature review. Drug Alcohol Depend. 2014;145:48-68. doi:https://doi.org/10.1016/j.drugalcdep.2014.10.012

50. Ti L, Buxton J, Harrison S, et al. Willingness to access an in-hospital supervised injection facility among hospitalized people who use illicit drugs. J Hosp Med. 2015;10(5):301-306. doi:https://doi.org/10.1002/ jhm.2344

Publisher's Note: Springer Nature remains neutral with regard to jurisdictional claims in published maps and institutional affiliations. 